\title{
Program Management Model for Health Behavioral Modification in Metabolic Risk of Public Hospitals, Bangkok
}

\author{
Ungsinun Intarakamhang ${ }^{1}$ \\ ${ }^{1}$ Behavioral Science Research Institute, Srinakharinwirot University, Bangkok, Thailand \\ Correspondence: Ungsinun Intarakamhang, Behavioral Science Research Institute, Srinakharinwirot University, \\ Bangkok, Thailand. E-mail: ungsinun@swu.ac.th
}

Received: May 12, 2012 Accepted: June 8, 2012 Online Published: August 17, 2012

doi:10.5539/ass.v8n11p170

URL: http://dx.doi.org/10.5539/ass.v8n11p170

\begin{abstract}
This action research is aimed to investigate the success of the program management for health behavioral modification (HBM) in Metabolic Syndrome (MS) of public hospitals in Bangkok which was granted by the $13^{\text {th }}$ district of National Health Security Office (NHSO), Thailand, for the total of 13 projects. The research process was divided into 3 phases as preparation, monitoring and conclusion phase. Data collection was done in the mid and at the end of the project through a 4-scale questionnaire and biomedical measurement. The project participants were project managers and their supervisors as 30 persons in each group, 120 hospital clients and 3,579 voluntary participants found to be at risk in MS. The research found that 1) the program management model was run completely from the beginning of training course for project managers and his staffs aimed to improve their potentiality in behavior modification based on "3-Self" according to PROMISE Model. Project monitoring was completed by providing at least 5 participation meetings through the project and knowledge sharing among projects 2) During the process of the project, it was found that attitude of clients, project managers and their supervisors towards CIPP Model were at excellent level (Mean = 3.43-3.56) and 3) after the project, it was found that the clients were better in 3 dimensions of health behaviors as increasing of self-efficacy, self-regulation and self-care $(\mathrm{p}<.05)$ though decreased in stress level, BMI, weight, waistline, blood pressure, Fasting Blood Sugar, HbA1c Triglyceride and cholesterol $(p<.05)$. Finding from interview revealed that success factors of the program included potentiality of teamwork, cooperation of participants, met-needs activities and the obstacles were less staffs in the project and diversity characteristics of the participants.
\end{abstract}

Keywords: project management, CIPP Model, behavior modification, metabolic syndrome

\section{Introduction}

In a decade ago, Thailand established several local units of health service and promotion in public, private and non-government organizations while health promotion products were also developed continuously. The reason for this fact was all sectors totally agreeing that ignorance of this situation could bring about wasting of national budget on public health remediation as well as economic development opportunity in the future (Manitch Teeratuntikanonda, 2011; Wichai Akeparakorn, 2010; Chanika Tuchinda, 2010). The health protection approach based on health literacy, thinking, skill and ability development was accepted to be a sustainable development regime for manpower and community promotion (Story et al., 2003; Tharntip and Varaporn, 2005). Severe chronic disease that could threaten human life like MS can be controlled by daily behavior modification. Anyway, more than 1.5 billion people were threatened by hypertension and about 7 million of them dead each year (Manitch Teeratuntikanonda, 2011). In Thailand within the last ten years period, 2000-2009, the number of patients with hypertension increased about 3.8 times and about 11.5 million persons of them were more than 15 years old. The prevalence of this disease was about 55.9 percent among the elderly aged more than 80 years. In 2009 , hypertension is still the $4^{\text {th }}$ main cause of Thai people's death as 24.66 following cancer and other tumors, accident and toxicity and Cardio Vascular Diseases (CVDs) respectively (Health Information and Communication Group, Department of Disease Control, 2009). It was also found that dead toll of Thai people by stroke was about 13,353 or average 36 persons per day. The number of stroke patients admitted in hospital increased 2.45 times within 10 years (Office of Public Relations, Department of Disease Control, 2009). This incidence caused government budget expenditure about 126,665.93 baht or 4,085 US \$ per head of patient per 
year (Wichai Akeparakorn, 2010). For other disease like diabetes, in 2009, there were 7,017 deaths from diabetes that equaled 19 persons a day while between 1999-2009 found the increased number of diabetes patients about 4.02 times and prevalence increased from 4.4 percent in 2008 to 6.9 percent in 2009. It can be predicted that there are about 3.46 million persons aged more than 15 years facing with diabetes (Office of Public Relations, Department of Disease Control, 2009). As same as obesity, it was also found in all age groups of people with increasing numbers, for example, between 2008 and 2009 it was found that Thai people who are in level 1 of obesity (BMI $>30 \mathrm{~kg} / \mathrm{cm}^{2}$ ) are 26.63 percent and 28.79 percent respectively (Division of Physical Activity and Health, 2010). This can confirm the cause of emerging MS as it associated with health behaviors especially consumption behavior, exercise and stress management.

There were several concepts and applications of HBM proposed by behavioral developer and psychologist such as "3-Self" concept which is composed of 1) self-efficiency in meaning of self-recognizing on HBM 2) self-regulation in meaning of monitoring of self health behavior and 3) self-care in meaning of taking care of own health condition. This concept is integrated with the Bandura's social cognitive learning theory, Orem's self-care theory and health promotion from food consumption, exercise and emotion of Ministry of Public Health to explain individual behavior. The 3-Self concept is believed that if there are sufficient of 3-Self on personal health behavior then the MS would change in to better quality of life (Ungsinun Intarakamhang, 2009, 2012). Thus, the hospital where conducted the program for HBM must also apply program management model according to PROMISE Model (Positive reinforce, Result-base management, Optimism, Motivation, Individual or client-centered and Self-esteem). The PROMISE Model is composed of psychological concept, behavior modification, and effective program management technique for successful program implementation. This model was also applied between 2008 and 2011 under supporting of the $13^{\text {th }}$ NHSO, Bangkok and found the high satisfaction level from program implementation among governmental sector, private sector, schools, universities and NGOs as result also showed the better change on health conditions such as decreasing of BMI, Fasting Blood Sugar and cholesterol. For 2011, research team extended the research implementation by applying 3-Self program based on PROMISE Model in public hospitals in Bangkok and concluded the success of the program to be a good practice model for health management support for other relevant sectors in the future.

\section{Objectives}

The main purpose of this study were 1) to develop program management model for HBM in public hospitals, 2) to evaluate success factors in HBM in public hospitals in Bangkok according to the conceptual framework of CIPP Model and 360 Degree Feedback during research conducted, and 3) to compare health behaviors and biomedical indicators before and after the program implemented.

\section{Methods}

\subsection{Setting}

Total 30 projects were operated in 15 hospitals in Bangkok granted by the $13^{\text {th }}$ district of NHSO on HBM in fiscal year 2011.

\subsection{Samples}

Sample groups were project managers and their supervisors as 30 persons for each, 120 clients and 3,579 voluntary participants who were screened and found for being risk of MSs on 4 main syndromes such as obesity, diabetes, hypertension and stroke.

\subsection{Dependent Variables}

Indicators for project successfulness covered 3-Self on health behavior such as self-efficacy, self-regulation and self-care, satisfaction on project participation and biomedical indicators such as Mass Body Index (BMI), body weight, waistline, waist hip ratio, Fasting Blood Sugar (FBS), HbA1c, cholesterol, Triglyceride and medical cost.

\subsection{Independent Variables}

Activities for behavior modification according to PROMISE Model were conducted at least 5 times by project managers and staffs for individual and group to promote 3-Self on health behavior according to PROMISE Model as follows.

(1) Positive reinforcement such as giving reward and compliment whenever participants can perform well aimed to encourage them to continue their right behaviors.

(2) Result based management was a main target for both program providers and clients for health behavior modification. 
(3) Optimism should be in staff's view in order to support them finding challenge in any obstacle they faced. Optimism also covers a belief on participant's efficiency for health behavior modification.

(4) Motivation should be considered by staffs to create new activities to stimulate participant's interesting and make better relationship between staffs and clients.

(5) Individual or client center means providing opportunity for participants to become leader on creating HBM activities by their owns and supporting their self-organizing on HBM activities such as objective setting, planning, activity designing, practicing and monitoring.

(6) Self-esteem means supporting clients to participate HBM activities and helping them to have self-recognizing on importance of being good health.

\subsection{Research Content and Learning Techniques}

Focus on client center based on appropriate time and content for all activities covering attitude and cognitive adjustment, motivation and reinforcement which was classified into 1) $30 \%$ of games and edutainment activities 2) $10 \%$ of health experts' knowledge sharing 3) $60 \%$ practice of "3-Self" (food, exercise and emotion) reinforcement program such as training, knowledge spot joining, individual or group consulting, advising, workshop, demonstrating, mentor creation, staff team assistant creation, team and network leader creation etc. All activities were aimed to generate a self-help network for sustaining good health activities.

\subsection{Research Tools}

(1) During project evaluation tools were a 4-scale questionnaire of PROMISE Model with 20 questions, a 4-rating scale questions owing to CIPP Model and in-depth interview form. Total reliability score for client of the questionnaire was .938 and for project manager was .924 .

(2) After project evaluation tool was "3-Self" health behavior which measured psychological condition and 3 dimensions of behavior with 17 questions of a 4-scale measurement form composing of self-efficiency with reliability score .73 , self-regulation with reliability score .80 and self-care with reliability score .85 .

\subsection{Descriptive Statistics}

T-test independent and One-way ANOVA was employed for data analysis while content analysis was applied for qualitative data narration.

\subsection{Conceptual Framework}

The relationship between independent variables and dependent variables was displayed in Figure 1. 
Input (Independent variables)

Behavior modification based on PROMISE model
training course for managers and their staffs
Positive-rein forcement, Result-based management,
Optimism, Motivation, Individual or client
center, Self-Esteems

Setting short and long term target with behavior modification planning for long term

3. Observed and recorded training with a tool of self health mapping

4. Learning from health experts

5. Heal th promotion activities such as stress relief, exercise and nutrition for self value recognizing

6. Consulting for individual and group in both face to face and calling

7. Home visiting partnership activity or buddy activity

8. Self empowerment by supporting client performance with providing tools such as blood testing kit, measurement, exercise suit, etc.

9. Motivation supporting such as rewards

10. Reinforcing with rewards, compliments and information whenever target achieved.

11. Playing game, competition for fun

12. Camping for right attitude building and "3-Self" practicing continuously.

13. Generating heal th leader to formulate the sustainable health network

14. Voluntary community supporting on health promotion

15. Self-evaluation activities and monitoring system

16. Group process solution or setting health monitoring group

17. Field trip for generating new experience

18. Creative activity training for self care challenging
Product (Dependent variables)

Increased behavior Indicators

Self-efficiency, Self-regulation, Self-care

Better biomedical Indicators

$\mathrm{BP}$, blood test, BMI, weight, waistline

Medical expenditure

\section{Impact}

1. Participants

- Feel satisfied toward the project

- Continuously join program

- Provide consultation for other people on health care

- Generate self-health network

2. Project manager

- Generate innovation and knowledge on behavior modification

- Increase skill on project management

- Need to run the project continuously

3. Supervisors

- Satisfy on project manager's work

- Accept that the project rel ating with organization policy

- Hospital gain trust from people.

- Continuous support the project

4. Research team

- gain better knowledge

5. National Health Security Office

- response the government policy on self-care behavior for local people, promote better health conditions and reduce unnecessary medical expenditure

Figure 1. Conceptual framework

\section{Results}

Descriptive data from total 3,579 participants, most of them were 2,527 female or 70.61 percent. There were 995 persons who aged between 50-59 years or 27.77 percent. 2,026 samples gained lower than bachelor degree or 56.61 percent. There were 1,514 persons who can claim for medical treatment rights since they are government officers and state enterprise workers by 42.30 percent. About 1,401 were found being risk for obesity or 39.15 percent, followed by risk taker for stroke, diabetes, and hypertension as $26.40,19.78,14.67$ percent respectively.

Result according to the objective 1. From project management model development on HBM in targeted public hospitals, Bangkok was as following in Figure 2. 


\section{Preparation phase by the research team}

1. Research team meeting for operation planning

2. Expert meeting for giving direction of advice for 30 projects

3. Project manager and team training on 3-Self and PROMISE based on client center

4. Project manager, project team and project supervisor meeting for setting agreement and project criteria

\section{Final Product}

1. Conclusion making which covered all phases of the project

2. Inspection conclusion making on HBM

3. A Project management manual on HBM

4. Network for HBM

5. An innovation gained from activities arrangement in targeted public hospitals

\section{Monitoring phase by the research team}

1. Inspector team meeting for mutual understanding in monitoring and evaluating criteria owing to CIPP Model

2. Inspecting for monitoring and evaluating in research areas (targeted hospitals) in order to know obstacles and provide suggestions

\section{Conclusion phase by the research team}

1. Project manager and research team meeting to conclude lesson learnt and share experiences

2. Concluding on efficiency and success factors as well as obstacles occurring in each project to be valuable finding for research discussion

Figure 2. Project management model for HBM

Success factors were evaluated according to the objective 2. In the monitoring phase, it was found that project participants, project managers and project supervisors gave highest score for the project successfulness (mean ranked between 3.23 and 3.71). It was no difference in scores among context, input and process factors but product factor scores were different $(\mathrm{p}<.01)$ as it was found that client group gave higher score than project managers and project supervisors as shown in Table 1.

Table 1. The comparison of the consistency of the evaluation scores among the clients, the program leaders, and the commanders of the program leaders using the ANOVA and the $t$-test

\begin{tabular}{|c|c|c|c|c|c|c|c|c|c|c|}
\hline \multirow{2}{*}{$\begin{array}{l}\text { Variables } \\
\text { (scale 1-4) }\end{array}$} & \multicolumn{2}{|c|}{$\begin{array}{c}\text { clients(1) } \\
n=120\end{array}$} & \multicolumn{2}{|c|}{$\begin{array}{l}\text { program leaders } \\
\text { (2) } n=30\end{array}$} & \multicolumn{2}{|c|}{$\begin{array}{l}\text { commanders } \\
\text { (3) } n=30\end{array}$} & \multirow{2}{*}{$\begin{array}{l}\text { F-test/ } \\
\text { (t-test) }\end{array}$} & \multicolumn{3}{|c|}{ Scheffe test } \\
\hline & Mean & S.D & Mean & S.D & Mean & S.D & & $1-2$ & $1-3$ & $2-3$ \\
\hline 1.Context & 3.50 & .35 & 3.53 & .30 & 3.62 & .29 & 1.57 & - & - & - \\
\hline 2.Input & 3.52 & .35 & 3.52 & .32 & 3.62 & .35 & 1.03 & - & - & - \\
\hline 3.Process & 3.51 & .33 & 3.42 & .42 & 3.53 & .49 & .72 & - & - & - \\
\hline 4.Product & 3.71 & .28 & 3.23 & .43 & 3.31 & .40 & $33.95 * *$ & $.47^{*}$ & $.39 *$ & - \\
\hline 5.Total & 3.56 & .27 & 3.43 & .32 & 3.52 & .31 & 2.39 & - & - & - \\
\hline 6.PROMISE & 3.54 & .32 & 3.56 & .34 & - & - & $(\mathrm{t}=.35)$ & - & - & - \\
\hline
\end{tabular}

Compared result between health behavior and biomedical indicators at the end of the project according to the third objective revealed that project participants had 1.Self-efficiency 2. Self-regulation 3.Self-care better than the previous time by $78.73 \%, 77.81 \%$,and $81.03 \%$, respectively. Moreover, project participants decreased in Fasting Blood Sugar, weight, BMI by $73.57 \%, 72.20 \%$ and $69.27 \%$, respectively by comparing with the previous time as shown in Table 2. 
Table 2. Number and Percentage of 3-self behaviors and biomedical indicators change after participating in the program compared with before participating in the program

\begin{tabular}{|c|c|c|c|c|c|c|c|}
\hline \multirow{2}{*}{$\begin{array}{c}\text { Change of } \\
\text { health risk indicators }\end{array}$} & \multirow{2}{*}{ Total n } & \multicolumn{2}{|c|}{ No change } & \multicolumn{2}{|c|}{ Increase } & \multicolumn{2}{|c|}{ Decrease } \\
\hline & & $\mathbf{n}$ & $\%$ & $\mathrm{n}$ & $\%$ & $\mathrm{n}$ & $\%$ \\
\hline 1. Self-efficacy & 3,579 & 375 & 10.48 & 2,818 & 78.73 & 386 & 10.79 \\
\hline 2. Self-regulation & 3,579 & 386 & 10.79 & 2,785 & 77.81 & 408 & 11.40 \\
\hline 3. Self-care & 3,579 & 313 & 8.74 & 2,900 & 81.03 & 366 & 10.23 \\
\hline 4. BMI & 2,886 & 366 & 12.68 & 521 & 18.05 & 1,999 & 69.27 \\
\hline 5. Systolic BP & 1,946 & 260 & 13.36 & 551 & 28.31 & 1,135 & 58.32 \\
\hline 6. Diastolic BP & 1,945 & 323 & 16.61 & 654 & 33.62 & 968 & 49.77 \\
\hline 7. Waistline (cm.) & 1,557 & 346 & 22.22 & 176 & 11.30 & 1,035 & 66.48 \\
\hline 8. Body weight (kg.) & 597 & 62 & 10.40 & 104 & 17.40 & 431 & 72.20 \\
\hline 9. Waist hip ratio & 210 & 13 & 6.20 & 54 & 25.70 & 143 & 68.10 \\
\hline 10.Fasting blood sugar (FBS ) & 667 & 24 & 3.60 & 197 & 29.50 & 446 & 66.90 \\
\hline 11.HbA1c & 280 & 6 & 2.14 & 68 & 24.29 & 206 & 73.57 \\
\hline 12.Cholesterol & 299 & 35 & 11.70 & 72 & 24.10 & 192 & 64.20 \\
\hline 13.Triglyceride & 153 & 1 & .70 & 64 & 41.80 & 88 & 57.50 \\
\hline 14.Medical cost per time (US \$) & 30 & 3 & 10.00 & 10 & 33.30 & 17 & 56.70 \\
\hline
\end{tabular}

Result from indicator testing between before and after the project showed that project participants could level up their self-efficiency, self-regulation and self-care by comparing with the prior. $\left({ }^{* *} \mathrm{p}<.01\right)$. They also decreased in BMI Systolic/Diastolic, waistline, weight, waist hip ratio, blood sugar level, Fasting Blood Sugar, cholesterol, Triglyceride and medical cost by comparing with the prior $(* * \mathrm{p}<.01)$ as shown in Table 3 .

Table 3. Comparison of 3-self behaviors and biomedical indicators between before and after participating in the program

\begin{tabular}{|c|c|c|c|c|c|c|c|c|c|}
\hline \multirow{2}{*}{ Health risk indicators } & \multirow{2}{*}{$\mathbf{n}$} & \multicolumn{2}{|c|}{ Before } & \multicolumn{2}{|c|}{ After } & \multirow{2}{*}{ M.D. } & \multirow{2}{*}{ df } & \multirow{2}{*}{ T-value } & \multirow{2}{*}{$\mathbf{r}$} \\
\hline & & $\overline{\bar{X}}$ & S.D. & $\bar{X}$ & S.D. & & & & \\
\hline 1. Self-efficacy & 3,579 & 14.01 & 2.52 & 16.25 & 2.19 & 2.24 & 3,578 & $51.67 * *$ & $.46^{* *}$ \\
\hline 2. Self-regulation & 3,579 & 13.45 & 2.76 & 15.79 & 2.37 & 2.34 & 3,578 & $50.50 * *$ & $.43^{* *}$ \\
\hline 3. Self-care & 3,579 & 19.37 & 3.69 & 22.43 & 3.19 & 3.06 & 3,578 & $53.33^{* *}$ & $.51 * *$ \\
\hline 4. BMI & 2,886 & 26.88 & 5.14 & 26.38 & 5.10 & .50 & 2,885 & $17.49^{* *}$ & $.95 * *$ \\
\hline 5. Systolic BP & 1,946 & 129.48 & 17.84 & 125.73 & 15.47 & 3.74 & 1,945 & $12.09^{* *}$ & $.62 * *$ \\
\hline 6. Diastolic BP & 1,945 & 79.36 & 10.65 & 77.90 & 9.87 & 1.45 & 1,944 & $6.92 * *$ & $.60^{* *}$ \\
\hline 7. Waistline (cm.) & 1,557 & 87.88 & 11.15 & 85.47 & 11.01 & 2.41 & 1,556 & $21.40 * *$ & $.93^{* *}$ \\
\hline 8. Body weight (kg.) & 597 & 71.80 & 13.39 & 70.39 & 13.24 & 1.40 & 578 & $12.12 * *$ & $.98^{* *}$ \\
\hline 9. Waist hip ratio & 210 & .89 & .09 & .87 & .07 & .02 & 209 & $3.77 * *$ & $.57^{* *}$ \\
\hline 10. Fasting blood sugar (FBS ) & 667 & 109.22 & 34.40 & 102.77 & 29.32 & 6.45 & 666 & $7.56^{* *}$ & $.77 * *$ \\
\hline 11. HbAlc & 280 & 9.07 & 3.89 & 8.12 & 1.91 & .94 & 279 & $4.41 * *$ & $.40^{* *}$ \\
\hline 12. Cholesterol & 299 & 221.24 & 42.62 & 207.19 & 39.26 & 14.05 & 298 & $7.43 * *$ & $.68^{* *}$ \\
\hline 13. Triglyceride & 153 & 157.56 & 191.81 & 135.73 & 72.54 & 21.82 & 152 & $1.71 * *$ & $.61^{* *}$ \\
\hline 14 Medical cost per time(US\$) & 30 & 190 & 95.72 & 143 & 63.86 & 166.89 & 29 & $3.03 * *$ & $.79 * *$ \\
\hline
\end{tabular}

* P-value $<.05$,

P-value $<.01$

Qualitative evaluation result revealed that most project managers, project supervisors and participants agreed that this project could respond their needs and leaded them to modify their behaviors effectively. This made research team leveling up significant skills properly according to PROMISE Model. It also leaded the team 
applying the success stories to be models for development in other organizations. The main factors influencing successfulness of the project were potentiality of research team, good cooperation among participants and appropriate various activities while obstacles found were less numbers of project members and significant difference among project participants.

\section{Discussion}

Most project participants were females. This indicated that females are more likely to realize on health care than males even males are more likely to face many risks such as alcohol drinking, smoking, stress from working. Thus, service unit should emphasize on males by persuading them to participate more on HBM activities according to "3-Self" and PROMISE Model.

Project evaluation according to CIPP Model revealed that project participants, project managers and project supervisors gave score higher than 70 percent of total score. Finding from interview explained this fact that HBM activities could serve the need of participants since it was found that the participants attained the activities 5 times continuously. Most of participants were those who are facing with unsolved chronic illnesses, having low income, being poor education and living in slum. For the satisfaction on activity arrangement, it was found that the provided activities suited to community life style while key persons in the community were developed along with the project implementation. Also, project managers had high experiences since they had chances to get training courses based on client center concept while research team worked very hard. Thus, all are the main conditions of satisfaction occurring among the participants.

Participants increased their scores on "3-Self" health and biomedical indicators by comparing with the prior before. This result was because of the application of PROMISE Model, the integrated model of management science, health and psychology. Also, all projects applied positive reinforcement, especially social reinforcement such as rewarding by other members when anyone in the group can achieve his/her goal. This finding was in accordance with the study of Mahanil (2009) who brought positive reinforcement approach to apply with patients in hospital. His study showed that the patients in a control group which positive reinforcement approach was applied had less Ferrum accumulation than those of other approaches applied. Important reinforcement behaviors cover complementation and encouragement. Calling for giving warm regard along with other reinforcement action done for two weeks continuously in a study of Boontem (2007) who studied the weight controlling among obesity factory workers showed that patients' knowledge on self-care had increased $(\mathrm{p}<.05)$ while their BMI was significantly decreased $(\mathrm{p}<.05)$. This finding was in accordance with a correlation research result of Cavalho and Hopko (2011) done with psychological students in the University of Tennessee, USA which showed that environmental arrangement of the university through positive reinforcement caused the decreasing of social alienation and depression behavior $(\mathrm{p}<.05)$. All above findings strongly confirmed the importance of positive reinforcement toward HBM. Building for self-efficacy in participants by applying successful model and experience sharing between project participants was a key success condition to build the participant's confidence. Along with self-regulation tools such as health behavior notebook of record and self-help group system, these tools could increase self-efficacy among the participants. Benefit of these techniques was also accordance with a study of Jakici (2003) who studied on exercise among obesity persons under the self-regulation concept by applying health behavior book of record along with information gained from home visiting. The finding showed that participants in control group could keep longer term of weight controlling. As same as a study of Chen and Yeh (2005) on stop-smoking program through Internet Assisted Instruction (IAI) for six weeks, this study also applied self-efficiency technique to make HBM for 77 students through encouragement support via web site, self-recording on health behavior and real time role model who showed the good step of stop-smoking. The finding showed that participants in control group could increase their self-efficiency while decreased time of smoking by comparing with those of uncontrolled group.

Main factor affecting successfulness of the project was the concept of PROMISE Model which was applied. Also, impression of the participants on teamwork and PROMISE Model activities such as positive reinforcement technique and motivation was another success factors. Furthermore, action of project managers and staffs in giving compliment and offering some rewards as well as giving opportunity for participants to present their capability could encourage the participants' confidence and allowed them to strongly join their hands in the project. This practice was in accordance with a study of Mikulas (1978: 89-94) who stated that "positive reinforcement can help contingency contracting being clearer" and helps a participant properly expecting output of the project he attended. While a technique of optimism and self-esteem building also allowed the participants to view a crisis as an opportunity and challenge them to realize that they are valuable for society thus, they have to take care themselves very well for providing benefit for all. This study also associated with a study of Chang (2001) who mentioned that optimism was an intelligent behavior. A person who is optimism will also consider 
unfortunate event as a specific event which will be overcome soon. He always accepts result of any event and tries his best for being better while pessimistic person tends to view that an unfortunate event is always still there and hard to overcome. This finding was also accordance with a study of Branden (1983: 8-10) who proposed the idea that a person who found of self-esteem will have clear characteristics including taking care himself very well for achieving good health.

\section{Conclusion}

It can be concluded that project management model on HBM in public hospitals can help the participants having better health behaviors as well as biomedical indicators. Main factor affecting successfulness of the project was the concept of PROMISE Model applied in HBM activities which could encourage the confidence and increase self-esteem among the participants for taking health care themselves continuously.

\section{References}

Boontem, P. (2007). The effect of weight control program on weight reduction of the overweight industrial workers. Nakhonpathom. Thesis (Master of Nursing Science). Graduate School of Mahidol University.

Branden, N. (1983). Honoring the self: The psychology of confidence and respect. Toronto: Bantam.

Carvalho, P. J., \& Hopko, R. D. (2011). Behavioral theory of depression: Reinforcement as a mediating variable between avoidance and depression. Journal of Behavior Therapy and Experimental Psychiatry. 42(2), 154-162. http://dx.doi.org/10.1016/j.jbtep.2010.10.001.

Chang, E. C. (2001). Optimism \& pessimism. London: Edward Brother, Inc.

Chanika Tauchinda. (2010). Over 5 million of Thai elementary school children-high school kids facing with obesity (in Thai). Retrieved January 12, 2011, from http://www.thaihealth.or.th/healthcontent/special_report/15598

Chen, H. H., \& Yeh, M. L. (2005). Developing and evaluation a smoking cessation program combined with an internet-assisted instruction program for adolescents with smoking. Retrieved February 12, 2010, from http://www.ncbi.nlm.nih.gov/entrez/query.gcgi?cmd=retrieve

Division of Physical Activity and Health. (2010). Obesity situation (in Thai). Bangkok: Ministry of Public Health.

Health Information and Communication Group, Department of Disease Control. (2009). Numbers and mortality rate per 100,000 persons classified by main causes of death 2005-2009 (in Thai). Bangkok: Ministry of Public Health.

Jakici, J. M.(2003). Exercise in the treatment of obesity. Endocrinal Metabolic North Am, 32(4), 967-980. http://dx.doi.org/10.1016/S0889-8529(03)00075-6

Mahanil, W. (2009). Effects of a teaching program on knowledge and self-care behavior regarding decreasing iron accumulation in the body of children with thalassemia at Nan Hospital Thailand. Nakhonpathom. Thesis (Master of Nursing Science). Graduate School of Mahidol University.

Manitch Teeratuntikanonda. (2011, May 17). Department of Disease Control: Care and would like Thais being healthy. Thai Post press.

Mikulas, William L. (1978). Behavior modification. New York: Harper \& Row.

Office of Public Relation, Department of Disease Control. (2009). Disease and health manual for mass media (2nd ed.). Bangkok: War Veteran Aid Organization Publishing.

Story, M. et al. (2003). Obesity in American-Indian Children: Prevalence, Consequences and Prevention. Preventive Medicine. 37, 3-12. http://dx.doi.org/10.1016/j.ypmed.2003.08.008

Tharntip, Mahawana, \& Varaporn, Sirisawang. (2005). Eating and physical exercise behavior of children in element school. Chiang Mai Med Bull, 44(2), 65-71.

Ungsinun Intarakamhang. (2009). 3-Self health behavioral change based on PROMISE model. Bangkok: Suk-khumvit print.

Ungsinun Intarakamhang. (2012, January). 3 Self behavior modification programs base on the PROMISE Model for clients at Metabolic Risk. Global journal of Health Science, 4(1), 204-210. http://dx.doi.org/10.5539/xxx.v4n1p00.

Wichai Akeparakorn. (2010). $4^{\text {th }}$ Thai health survey 2008-2009. Nonthaburi: The Graphico System co.ltd. 